This is an author produced version of a paper published in Archives of Physical Medicine and Rehabilitation. This paper has been peer-reviewed but does not include the final publisher proof-corrections or journal pagination.

Citation for the published paper:

Gerdhem, Paul and Ringsberg, Karin A and

Akesson, Kristina.

"The relation between previous fractures and physical

performance in elderly women"

Archives of Physical Medicine and Rehabilitation, 2006, Vol: 87, Issue:7, pp. 914-17.

http://dx.doi.org/10.1016/j.apmr.2006.03.019

Access to the published version may require journal subscription. Published with permission from: Elsevier 


\section{The relation between previous fractures and physical performance in}

\section{elderly women.}

Paul Gerdhem, MD, PhD, Karin AM Ringsberg, physiotherapist, PhD, Kristina Åkesson,

MD, PhD, Department of Orthopaedics, Malmö University Hospital, Lund University, SE 205

02 Malmö, Sweden.

Running title: Physical performance after fracture in elderly women

Key words: Physical performance, fracture, elderly, women

Abstract words: 198

Text words (excluding abstract): 2265

Graphics: 2 tables, 1 figure.

References: 27

Correspondence to: Paul Gerdhem, Department of Orthopaedics, Malmö University Hospital, Lund University, SE 20502 Malmö, Sweden.

Phone: +46(0)40-331000

Fax: +46(0)40-336200

E-mail: paul.gerdhem@skane.se

Reprints will not be available from the authors

No part of this manuscript has been published earlier

Acknowledgement: Financial support was obtained from the Swedish Medical Research

Council and Trygg-Hansa Research Fund. 


\section{Abstract}

Objective: To examine the association between previous fracture and different aspects of physical performance.

Design: Population-based retrospective study.

Setting: Orthopaedic research department.

Participants: 1044 randomly selected women, all 75 years old and participants of the Malmö Osteoporosis Prospective Risk Assessment (OPRA) study.

Outcome measures: Type of and time since any previous fracture event, were compared to tests on physical performance function (Romberg test, computerized sway test, gait speed, and questionnaire) at the age of 75.

Result: Women with no previous fractures $(n=505)$ had a better median Romberg balance (lower; upper quartile) of 94 seconds $(75 ; 118)$ than women with one, two, three or more fractures, who had a median balance of 88 seconds (71;111), 85 seconds $(68 ; 107)$ and 81 seconds (65;109), respectively (Kruskal-Wallis ANOVA p=0.002). Balance was inferior in women having sustained a previous fracture between the age of 65 and 75 compared to women with no previous fractures or fractures before the age of 65. Gait speed and questions on tendency to fall followed the same pattern. The computerized sway test could not differ between women with and without previous fractures.

Conclusion: Poor physical performance is associated with previous fractures. Inferior physical performance may exist up to 10 years after a fracture.

Key words: Balance, fracture, elderly, women 


\section{INTRODUCTION}

Several factors make up the risk for fracture at old age ${ }^{1}$. The most widely studied is low bone mass. In addition, decreased balance is an important risk factor for fracture ${ }^{2,3}$ and impaired balance may also be more important than osteoporosis at old age ${ }^{4}$. Balance is a complex function and is composed by visual and sensory inputs, and vestibular and neuromuscular function ${ }^{5}$. Among reported risk factors for fracture are also slow gait and decreased vision ${ }^{2,6}$, ${ }^{7}$, both measures that are related to balance. There are several reports concerning decreased balance and function up to some years after a fracture ${ }^{8-13}$. There is only one study covering a longer time span (17 years) ${ }^{14}$, but none with an even longer perspective. Also, balance and function seem to be less affected after a wrist fracture than after a hip, arm or vertebral fracture ${ }^{13,14}$.

Our aim with this study was to investigate balance, and other physical performance variables, (gait performance and falling tendency) after a previous fracture in elderly women. Do women with earlier fractures have inferior physical performance at the age of 75 compared to women with no previous fracture? If so, is the inferior physical performance a condition affected by type of and time from fracture occurrence? 


\section{INDIVIDUALS AND METHODS}

\section{Individuals}

From December 1995 to May 1999, 75-year old women were randomly recruited from the city files of Malmö, Sweden to participate in the Malmö Osteoporosis Prospective Risk Assessment (OPRA) study ${ }^{15}$. Of the initially invited 1604 women, 1044 women (65\%) participated in the baseline investigation. Five hundred sixty women did not participate; 13 died shortly after the invitation, 139 could not come due to illness, 376 women were not interested or could not attend due to reasons other than illness, and 32 women were not reached despite repeated letters and phone calls ${ }^{15}$. Of the participants, 40 went through a modified examination at home.

The Ethics Committee of Lund University approved the study, and informed consent was obtained from all subjects.

\section{Fractures}

All x-rays and x-ray files have been saved since the turn of the previous century at the Malmö University Hospital, which makes it possible to trace all women with fractures that has been x-rayed at our hospital. In addition, each woman was asked to record age and type of any previous fracture, and where fracture treatment had taken place. If a self-assessed fracture could not be verified in the x-ray archives, an additional search was done in the files of the department of orthopaedics unless fracture treatment had been taken place elsewhere. In these cases no further verification was made. For this specific study, a fracture was considered as occurred even if the participant had a self-assessed or a fracture registered in the x-ray archives. 
Of the women that had at least one self-assessed fracture in the questionnaire, $21 \%$ had no fracture registered in the hospital files and had not registered the fracture as treated elsewhere. $16 \%$ of the women with no self-assessed fracture in the questionnaire had in fact had at least one fracture according to the x-ray archive.

\section{Balance}

The two different balance tests used here has been described earlier ${ }^{15}$. The Romberg test for standing balance consists of 5 parts, (1) standing on both legs with feet together and eyes closed, the time until balance was lost, or maximum 60 seconds was recorded, (2-5) standing on one leg at a time with eyes open or closed, maximum time in these tests were 30 seconds. In case of a test result of less than 5 seconds in one of the standing balance tests, this was registered as 0 . Three trials per test were allowed; the best was registered. The results were added and the maximum was 180 seconds (for example; in the case of a failure of one onelegged stance test but success in the other four parts, the maximum would be 150 points instead of 180). The Romberg test was performed and a score was achieved by 1018 women. Intraclass correlation coefficients for Romberg inter-rater reliability have been reported to be between 0.73 to 0.93 and for intra-rater reliability between 0.95 and $0.99^{16}$.

Chattecx ${ }^{\circledR}$ computerized balance system (Chattanooga Group, Inc. USA) consisting of independent force measuring transducers (foot-plates) for the toe and heel of each foot, was used to test static and dynamic balance. Each subject was assessed by four different 25-second standing balance tests: (i) stable platform with eyes open, (ii) stable platform with eyes closed, (iii) platform gliding horizontally, backwards and forwards, eyes closed (iv) platform moving up and down, eyes open. At least 1 of these 4 parts was performed by 979 women. A 
sway index is calculated by this equipment by using the standard deviation of the time and the distance a subject spends away from her centre of balance for each test. Intraclass correlation coefficients for retest reliability of the Chattecx ${ }^{\circledR}$ computerized balance system have been reported to be $>0.65$ for static tests and $>0.35$ for dynamic tests ${ }^{17,18}$.

\section{Gait}

The women were instructed to walk as fast as they could in their ordinary shoes back and forth a 15 meter long distance (total distance 30 meters). The turn was included in the time recorded. The women were closely monitored during the test. Gait speed was performed in 983 women.

\section{Questionnaire}

A perceived tendency to fall or not was registered. This question was added during the course of the study and answers were available in 903 women.

\section{Statistics}

Comparisons between groups were made with non-parametric tests (Mann-Whitney U-test, Kruskal Wallis), parametric tests (t-test, ANOVA) or in the case of dichotomous variables, a Chi-square-test. $\mathrm{P}<0.05$ was considered significant. The women were for comparisons divided into those with or without any fracture, women with one, two or three or more previous fractures, and according to some fracture types (hip, vertebral, wrist or proximal humerus fractures). The women were also divided into groups according to age when the last fracture occurred (younger than 55, 55-59, 60-64, 65-69 and 70-75 years). 


\section{Results}

All women were 75 years at the examination date (range 75.0-75.9 years). We found that 535 of 1044 women had had a previous fracture. In $82 \%$ of the women with at least one fracture the last fracture was sustained after the age of 55. A tendency to fall was perceived by 372 of 903 women (41\%). The results from the sway test and gait were normally distributed, but the Romberg balance test had a skew distribution and therefore non-parametric tests were used for the statistical calculations of this variable.

\section{Romberg test}

The group of women with a previous fracture had an inferior result of the Romberg test when compared to the group of women without previous fractures (Table 1). Women with a previous hip fracture had an inferior result compared to women with no fracture or no previous hip fracture (Table 1). When subdivided into groups according to number of previous fractures we found that each additional fracture was associated with a further decrease of the Romberg test result (Table 2).

In order to elucidate the possible long-time effect of a fracture on balance ability we looked at the time between the examination and the previous last fracture. Women with fractures after the age of 65 had an inferior Romberg balance compared to women with no fracture history. Women with the last fracture before the age of 65 did not have an inferior balance compared to women without previous fractures (Figure1). Excluding women where the last fracture was a lower extremity fracture did not change the result, with the same pattern (data not shown). Women with fractures earlier in life had had fewer fractures than women with their last fractures at a higher age (data not shown). 


\section{Sway test}

The computerized sway test was unable to distinguish between participants with and without a fracture history with p-values ranging between 0.08-0.94.

\section{Gait}

The group of women with any previous fracture or wrist fracture did not have slower gait than women with no previous fracture. Women with hip, vertebral and proximal humerus fractures had slower gait speed than women without a previous fracture (Table 1). Each additional fracture was associated with slower gait (Table 2).

\section{Questionnaire}

A perceived tendency to fall was more common in women with any fracture (48\%), previous hip (57\%), wrist (48\%) or vertebral fracture (72\%) compared to women with no previous fractures (34\%) $(\mathrm{p}<0.001, \mathrm{p}=0.002, \mathrm{p}<0.001$ and $\mathrm{p}<0.001$, respectively). A perceived tendency to fall in women with proximal humerus fractures (49\%) was not significantly lower ( $p=0.051$ ) when compared to women with no previous fractures. Each additional fracture was associated with a higher frequency of women with a self-perceived tendency to fall (44\%, $45 \%$ and 64\%, respectively) compared to women without a previous fracture (34\%) (Chisquare, $\mathrm{p}<0.001)$. Women with a perceived tendency to fall had a lower median Romberg test result than women without any perceived tendency to fall (81 seconds; range 0-143, 97 seconds; range $0-159$, respectively, $\mathrm{p}<0.001$ ). 


\section{Discussion}

We have in this population-based study found that 75-year old women with earlier fractures have inferior balance than women with no previous fractures. Women with several previous fractures have a poorer balance performance than women with few or no previous fractures at the age of 75 . Women that had their last fracture before the age of 65 have a balance similar to women without a previous fracture. This study is, as far as we know of, the only one covering the association between balance and previous fractures with a time-span of up to 75 years.

The simple Romberg test was able to discriminate between women with and without previous fractures, which is in concordance with others that have compared differences in balance, gait or other measures of physical performance up to 17 years after a fracture history ${ }^{9,11,13,14}$. The Romberg test differences between women with specific types of fractures and women without fractures were in this study up to 17 seconds and with corresponding gait speed results that were up to $12 \%$ lower (Table 1 ). These differences may be clinically significant. The Romberg test has been frequently used since it is a simple measure of balance function. It has been shown to predict falls in the OPRA cohort ${ }^{19}$ and injurious falls in another cohort ${ }^{20}$. Various other balance tests have been shown to predict falls or fractures in other cohorts ${ }^{6,21}$, 22.

The seemingly more sophisticated method, the computerized balance platform, measuring postural sway, could not discriminate women with and without previous fractures in this study. A recent publication from the OPRA cohort could not find any predictive value for falls or fractures during a one-year prospective follow-up for this specific computerized 
balance plate ${ }^{19}$. However, other sway tests have been able to discriminate between subjects with and without a recent fracture ${ }^{10,11}$ and also have a prospective fall- ${ }^{23}$ and fracturepredicting ability ${ }^{3}$. It therefore seems important how sway is measured.

We found normalized Romberg balance when the last fracture event occurred before the age of 65 (Figure 1). There are several possible explanations for this finding. Fractures sustained at earlier ages may occur in women with a more physically active life style (therefore having better balance), who at the same time exposes themselves to a greater risk of injury in for example sports. A lower limb disability, for example due to a lower limb fracture, may affect the Romberg balance result. A recent hip fracture could affect balance ${ }^{11,13}$ and functioning ${ }^{12,}$ 14, 24 more than for example a recent wrist fracture ${ }^{9,13}$. However, when all lower extremity fractures were excluded the result was the same, which indicates that fracture location may be of less importance for the results achieved in this study. Since each additional fracture was associated with a decreased Romberg test result (Table 2), we cannot exclude that a higher number of previous fractures in women after the age of 65 also could affect these results. Another possible explanation could be that a fracture after the age of 65 gives a higher level of dysfunction and therefore a more impaired balance.

Gait speed correlated fairly well to balance $(r=-0.50)$ in a subset of women taking part in the OPRA study ${ }^{25}$. That gait shows the same pattern of change in reference to previous fractures is therefore not surprising. This is also consistent with the only prospective studies ( 0.5 and 8 years follow-up) on the effect of fracture on physical performance ${ }^{12,13}$. A smaller effect of wrist fractures on physical performance (including gait and balance) is also consistent with other reports $9,13,14$. 
In a retrospective study there is always the question on what comes first, impaired balance leading to a fracture, or fracture leading to impaired balance. Nevertheless, our study clearly demonstrates that impaired balance is associated with previous fracture. Impaired balance is a risk factor for future fractures ${ }^{1,19,26}$. An improvement of balance may therefore be of outmost importance in patients with several previous fractures. Self efficacy, in this study represented by the question on perceived tendency to fall, may also be important to address.

This study has some limitations. The attendance rate was high (65\%), but the non-attendees may represent a frailer subgroup of the population and as many as $27 \%$ claimed illness as a reason not to participate ${ }^{15}$. The data may not be valid for this frailer subgroup. One has also to be aware of the drawbacks of retrospective fracture registration. However, considering the retrospective nature of this study, we believe that it is very difficult, or impossible to achieve $100 \%$ verification of fractures covering a time-span of up to 75 years. In this study we therefore accepted that $21 \%$ of the women had fractures that were not objectively verified. Even if not recorded by the women, fractures may have been treated elsewhere, considering the long time period this study covers.

Valid information on the circumstances that lead to the fracture was not available. Some fractures may have been due to traffic accidents, but even if so, such a fracture would presumably give an effect on balance due to disability or fear of falling.

Inferior balance is associated with falling tendency ${ }^{21}$, which is one of the more important risk factors for fractures ${ }^{2,27}$ and interventions for prevention of falls includes balance training, which may be successful also at higher ages ${ }^{26}$. 
In summary, in elderly women previous fractures are associated with inferior physical performance and a perceived tendency to fall. Physical performance is mostly impaired in those with hip and multiple fractures. An association between a fracture and decreased physical performance may last for several years. In the elderly, fracture treatment (medical, surgical and physiotherapeutic) should possibly aim at minimising the effects on physical function, which also may be beneficial in decreasing future fracture risk. 
Table 1. Inferior balance (Romberg test; 0-180 seconds;s) was seen in women with a fracture history compared to women without any fractures. Slower $30 \mathrm{~m}$ gait was seen in women with previous hip, vertebral or proximal humerus fractures when compared to women without fractures. The women are divided into subgroups according to previous fracture history and compared to women with no previous fractures.

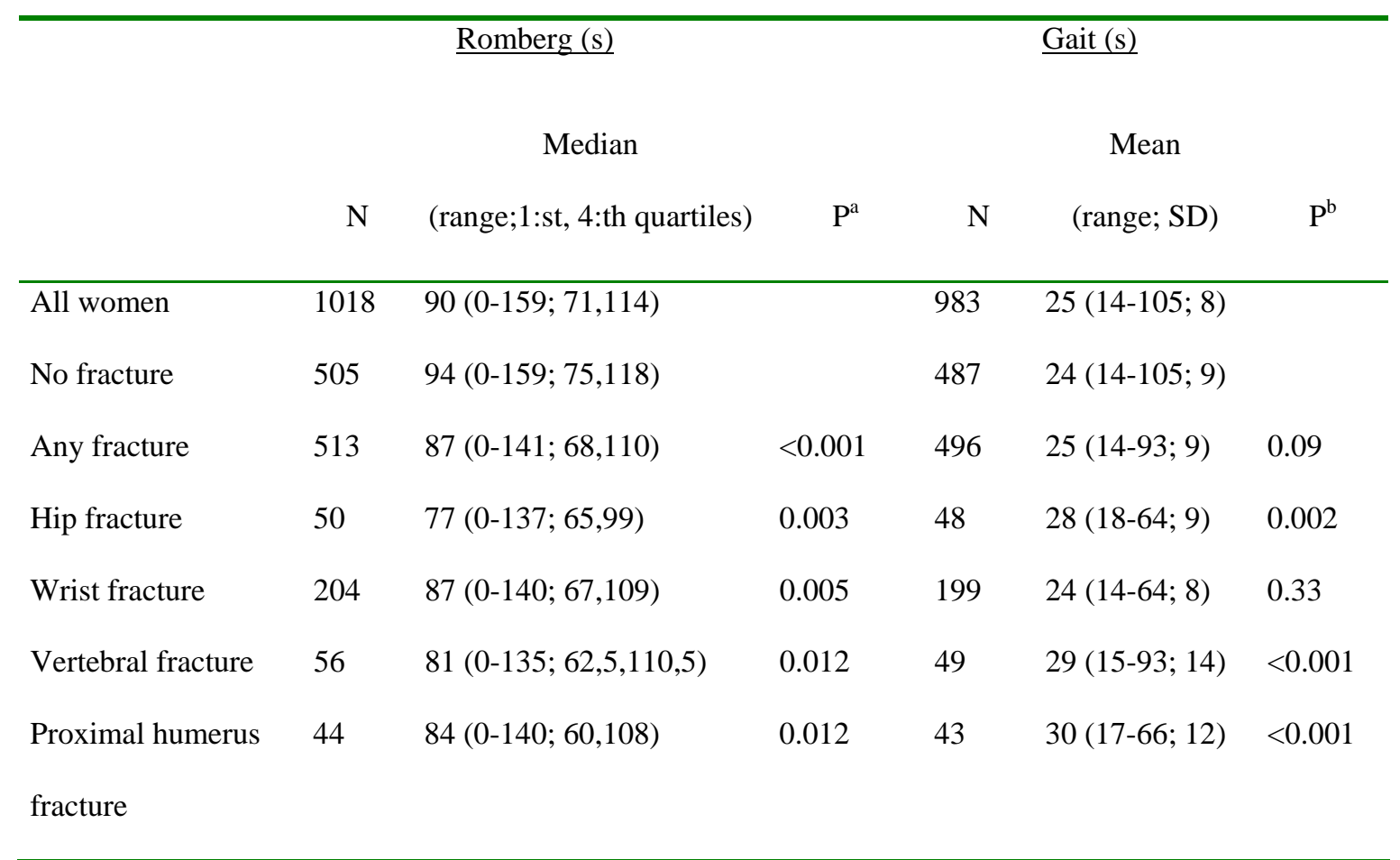

\section{${ }^{\mathrm{a}}$ Mann-Whitney U-test.}

$b_{\text {t-test. }}$ 
Table 2. With each additionally sustained fracture the Romberg test result (0-180 seconds;s) decreased (Kruskal Wallis $\mathrm{p}=0.002$ ). The same pattern was seen with gait speed at the $30 \mathrm{~m}$ walk (ANOVA $\mathrm{p}=0.002)$.

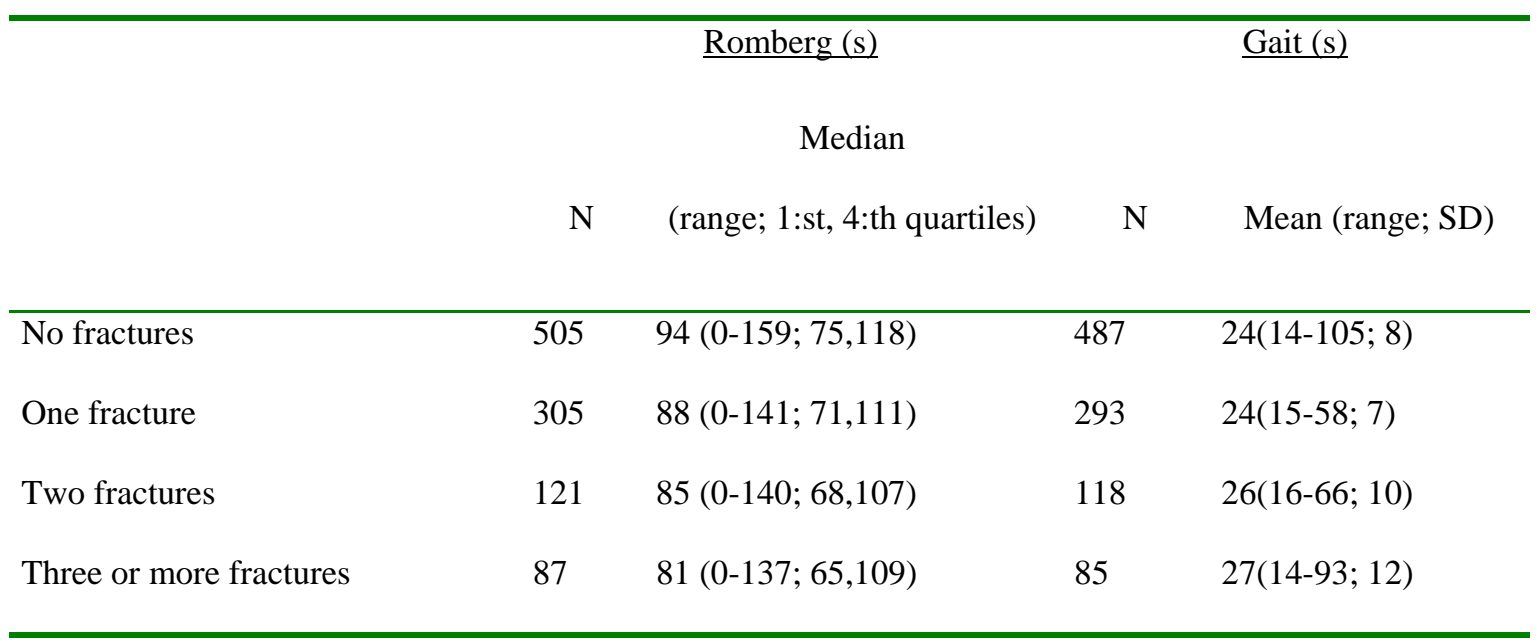


Figure legends

Figure 1. Women with no previous fractures (No fx) had better balance, measured with the Romberg test (0-180 seconds), than women with their last fracture at 65-75 years of age. There was no difference in balance between women with a fracture before the age of 65 and women with no previous fractures. $\mathrm{P}=$ level of significance for comparisons with women without previous fractures (Mann-Whitney U-test). $\mathrm{N}=$ number of women in each group. 


\section{References}

1. Espallargues M, Sampietro-Colom L, Estrada MD, Sola M, del Rio L, Setoain J, et al. Identifying bonemass-related risk factors for fracture to guide bone densitometry measurements: a systematic review of the literature. Osteoporos Int 2001;12:811-22.

2. Dargent-Molina P, Favier F, Grandjean H, Baudoin C, Schott AM, Hausherr E, et al. Fall-related factors and risk of hip fracture: the EPIDOS prospective study. Lancet 1996;348:145-9.

3. Nguyen T, Sambrook P, Kelly P, Jones G, Lord S, Freund J, et al. Prediction of osteoporotic fractures by postural instability and bone density. Bmj 1993;307:1111-5.

4. Gardsell P, Johnell O, Nilsson BE, Nilsson JA. The predictive value of fracture, disease, and falling tendency for fragility fractures in women. Calcif Tissue Int 1989;45:327-30.

5. Alexander NB. Postural control in older adults. J Am Geriatr Soc 1994;42:93-108.

6. Dargent-Molina P, Douchin MN, Cormier C, Meunier PJ, Breart G. Use of clinical risk factors in elderly women with low bone mineral density to identify women at higher risk of hip fracture: The EPIDOS prospective study. Osteoporos Int 2002;13:593-9.

7. Felson DT, Anderson JJ, Hannan MT, Milton RC, Wilson PW, Kiel DP. Impaired vision and hip fracture. The Framingham Study. J Am Geriatr Soc 1989;37:495-500.

8. Crilly RG, Delaquerriere Richardson L, Roth JH, Vandervoort AA, Hayes KC, Mackenzie RA. Postural stability and Colles' fracture. Age Ageing 1987;16:133-8.

9. Ringsberg K, Johnell O, Obrant K. Balance and speed of walking of women with Colle's fractures. Physiotherapy 1993;79:7689-7692.

10. Lord SR, Sambrook PN, Gilbert C, Kelly PJ, Nguyen T, Webster IW, et al. Postural stability, falls and fractures in the elderly: results from the Dubbo Osteoporosis Epidemiology Study. Med J Aust 1994;160:684-5, 688-91.

11. Jarnlo GB, Thorngren KG. Standing balance in hip fracture patients. 20 middle-aged patients compared with 20 healthy subjects. Acta Orthop Scand 1991;62:427-34.

12. Marottoli RA, Berkman LF, Cooney LM, Jr. Decline in physical function following hip fracture. J Am Geriatr Soc 1992;40:861-6.

13. Greendale GA, DeAmicis TA, Bucur A, Bretsky P, Rowe JW, Reuben DB, et al. A prospective study of the effect of fracture on measured physical performance: results from the MacArthur Study--MAC. J Am Geriatr Soc 2000;48:546-9.

14. Greendale GA, Barrett-Connor E, Ingles S, Haile R. Late physical and functional effects of osteoporotic fracture in women: the Rancho Bernardo Study. J Am Geriatr Soc 1995;43:955-61.

15. Gerdhem P, Ringsberg KA, Magnusson H, Obrant KJ, Akesson K. Bone mass cannot be predicted by estimations of frailty in elderly ambulatory women. Gerontology 2003;49:168-72.

16. Franchignoni F, Tesio L, Martino MT, Ricupero C. Reliability of four simple, quantitative tests of balance and mobility in healthy elderly females. Aging (Milano) 1998;10:26-31.

17. Condron JE, Hill KD. Reliability and validity of a dual-task force platform assessment of balance performance: effect of age, balance impairment, and cognitive task. J Am Geriatr Soc 2002;50:157-62.

18. Levine D, Whittle MW, Beach JA, Ollard PG. Test-retest reliability of the Chattecx Balance System in the patient with hemiplegia. J Rehabil Res Dev 1996;33:36-44.

19. Gerdhem P, Ringsberg KA, Akesson K, Obrant KJ. Clinical history and biologic age predicted falls better than objective functional tests. J Clin Epidemiol 2005;58:226-32.

20. Vellas BJ, Wayne SJ, Romero L, Baumgartner RN, Rubenstein LZ, Garry PJ. One-leg balance is an important predictor of injurious falls in older persons. J Am Geriatr Soc 1997;45:735-8.

21. Tinetti ME, Speechley M, Ginter SF. Risk factors for falls among elderly persons living in the community. N Engl J Med 1988;319:1701-7.

22. Stalenhoef PA, Diederiks JP, Knottnerus JA, Kester AD, Crebolder HF. A risk model for the prediction of recurrent falls in community-dwelling elderly. A prospective cohort study. J Clin Epidemiol 2002;55:1088-94.

23. Stel VS, Smit JH, Pluijm SM, Lips P. Balance and mobility performance as treatable risk factors for recurrent falling in older persons. J Clin Epidemiol 2003;56:659-68.

24. Sernbo I, Johnell O. Consequences of a hip fracture: a prospective study over 1 year. Osteoporos Int 1993;3:148-53.

25. Ringsberg K, Gerdhem P, Johansson J, Obrant KJ. Is there a relationship between balance, gait performance and muscular strength in 75-year-old women? Age Ageing 1999;28:289-93. 
26. Gillespie LD, Gillespie WJ, Robertson MC, Lamb SE, Cumming RG, Rowe BH. Interventions for preventing falls in elderly people. The Cochrane Database of Systematic Reviews. In: The Cochrane Library: John Wiley and Sons Ltd, 2003.

27. Cummings SR, Nevitt MC, Browner WS, Stone K, Fox KM, Ensrud KE, et al. Risk factors for hip fracture in white women. Study of Osteoporotic Fractures Research Group. N Engl J Med 1995;332:767-73. 
